\title{
Development of the control algorithm of processes of intensive hygrothermal impact on capillary and porous materials in the conditions of the vacuum
}

\author{
Ludmila Larina ${ }^{1, *}$, Dmitriy Ruslyakov ${ }^{1}$, Olga Tikhonova $^{1}$, and Sergey Morozov ${ }^{1}$ \\ ${ }^{1}$ Don State Technical University, 344002 Gagarin Square, 1, Rostov-on-Don, Russian Federation
}

\begin{abstract}
Objective of this research is creation of an algorithm of a control system of the modes of the intensive hygrothermal influence (IGI) in the conditions of a vacuum when performing the corresponding operations: moistening; the subsequent, if necessary, cyclic drying from within preparation of top of footwear; damp thermal treatment on universal installation with adjustable parameters of a working environment. For assessment of quality of the intensified hygrothermal impact on preparations of top of footwear the integrated criteria of efficiency of processes were used. Ensuring automatic control of parameters of processes of IGV on preparations of top of footwear in universal vacuum installation will allow to control quality of preparations upon transition from performance of one operation to another according to standard manufacturing techniques of footwear.
\end{abstract}

\section{Introduction}

The Intensive hygrothermal Influence (IGI) on capillary and porous materials to which also genuine leather belongs provides change to the best physicomechanical indicators of the processed materials [1]. It is known $[2,3]$ that for achievement of the indicators of physicomechanical properties of previously vacuumized skin demanded by manufacturing techniques [30] of footwear except the coordination of indicators of temperature and pressure of a working environment providing her required relative humidity it is necessary to regulate also time of processing. And, depending on the purpose of the carried-out hygrothermal influence increases in molding capacity of skin or a form stability of finished products it is required to change to the best either the conditional module of elasticity of material, or size of residual deformation, and their best values after pumping out and the subsequent hygrothermal processing fall on various values of time of processing in the range from 2 up to 8 minutes in table 1 [5].

As appears from experimental data of dependence, full and residual lengthenings at 10 MPas from time of vacuum and sorption moistening of skin of chromic tanning have obviously expressed maximum corresponding to moistening within 4 minutes and to a moisture additional weight within $18-19 \%$. At a traditional way of moistening the moisture additional weight in $15 \%$ Excess of the optimum humidity received at a vacuum and sorption way of moistening for $3-4 \%$ is optimum is explained, obviously, by features of penetration and effect of moisture on internal structure of skin at this way of moistening.

Table 1. Change of Physicomechanical Indicators of Samples of Skin of Chromic Tanning depending on duration of vacuum and sorption moistening

\begin{tabular}{|c|c|c|c|c|}
\hline \multirow{2}{*}{ Indicators } & \multicolumn{4}{|c|}{ Time of moistening, min. } \\
\hline & 2 & 4 & 6 & 8 \\
\hline \multirow{4}{*}{$\begin{array}{l}\text { Additional weight } \\
\text { of moisture, } \% \\
\text { in longitudinal } \\
\text { samples } \\
\text { in cross samples } \\
\text { average }\end{array}$} & & & & \\
\hline & $15,0 \pm 1,0$ & $18,8 \pm 1,2$ & $19,0 \pm 1,2$ & $11,6 \pm 0,7$ \\
\hline & $16,4 \pm 1,0$ & $19,7 \pm 1,8$ & $16,2 \pm 1,0$ & $11,6 \pm 0,7$ \\
\hline & $15,7 \pm 1,0$ & $19,3 \pm 1,5$ & $17,6 \pm 1,1$ & $11,6 \pm 0,7$ \\
\hline \multirow{4}{*}{$\begin{array}{l}\text { Residual } \\
\text { lengthening at } 10 \\
\text { MPas, \% } \\
\text { longitudinal } \\
\text { cross } \\
\text { average }\end{array}$} & & & & \\
\hline & $14 \pm 1$ & $18 \pm 2$ & $16 \pm 1$ & $14 \pm 1$ \\
\hline & $18 \pm 1$ & $28 \pm 2$ & $23 \pm 2$ & $13 \pm 1$ \\
\hline & $16 \pm 1$ & $23 \pm 2$ & $19,5 \pm 1,5$ & $13,5 \pm 1$ \\
\hline \multirow{4}{*}{$\begin{array}{l}\text { Full lengthening } \\
\text { at } 10 \mathrm{MPas}, \% \\
\text { longitudinal } \\
\text { cross } \\
\text { average }\end{array}$} & & & & \\
\hline & $22 \pm 2$ & $29 \pm 2$ & $25 \pm 2$ & $25 \pm 2$ \\
\hline & $28 \pm 2$ & $52 \pm 3$ & $42 \pm 3$ & $34 \pm 2$ \\
\hline & $25 \pm 2$ & $40,5 \pm 2,5$ & $33,5 \pm 2,5$ & $29,5 \pm 2$ \\
\hline \multirow{4}{*}{$\begin{array}{l}\text { Loading at a gap, } \mathrm{H} \\
\text { longitudinal } \\
\text { cross } \\
\text { average }\end{array}$} & & & & \\
\hline & $290 \pm 16$ & $240 \pm 9$ & $230 \pm 17$ & $215 \pm 14$ \\
\hline & $236 \pm 15$ & $180 \pm 8$ & $145 \pm 11$ & $140 \pm 9$ \\
\hline & $263 \pm 15$ & $210 \pm 8$ & $188 \pm 14$ & $180,5 \pm 11,5$ \\
\hline \multirow{4}{*}{$\begin{array}{l}\text { Strength at } \\
\text { stretching, MPa } \\
\text { longitudinal } \\
\text { cross } \\
\text { average }\end{array}$} & & & & \\
\hline & $33,3 \pm 2,1$ & $30,0 \pm 1,2$ & $28,3 \pm 2,0$ & $28,9 \pm 1,7$ \\
\hline & $29,5 \pm 1,8$ & $23,5 \pm 1,1$ & $22,0 \pm 2,0$ & $18,9 \pm 1,5$ \\
\hline & $31,4 \pm 2,0$ & $27 \pm 1,1$ & $25,0 \pm 2,0$ & $23,9 \pm 1,6$ \\
\hline \multirow{2}{*}{$\begin{array}{l}\text { Lengthening at a } \\
\text { gap, } \% \\
\text { longitudinal }\end{array}$} & & & & \\
\hline & $66 \pm 4$ & $66 \pm 5$ & $63 \pm 4$ & $59 \pm 4$ \\
\hline
\end{tabular}

\footnotetext{
*Corresponding author: Ludmila-larina2010@,mail.ru
} 


\begin{tabular}{|l|c|c|c|c|} 
cross & $75 \pm 5$ & $75 \pm 5$ & $72 \pm 4$ & $55 \pm 3$ \\
average & $71 \pm 5$ & $71 \pm 5$ & $68 \pm 4$ & $57 \pm 4$ \\
\hline $\begin{array}{l}\text { Conditional } \\
\text { module of }\end{array}$ & & & & \\
elasticity, MPa & & & & \\
longitudinal & $40,0 \pm 2,5$ & $27,7 \pm 1,7$ & $40,4 \pm 2,5$ & $33,8 \pm 2,1$ \\
cross & $28,1 \pm 1,7$ & $15,2 \pm 0,9$ & $17,5 \pm 1,0$ & $23,7 \pm 1,5$ \\
average & $34 \pm 2,1$ & $21,5 \pm 1,3$ & $29 \pm 1,8$ & $28,8 \pm 1,8$ \\
\hline
\end{tabular}

Therefore, depending on the processing purpose, it is required to maintain not only the required parameters of processes [5,6], but also to fix time of processing [7] taking into account a prevalence of these or those indicators in total defining processes and products of processing as systems with the set properties.

For assessment of quality of the intensified hygrothermal impact on preparations of top of footwear in works [8], the integrated criteria of efficiency of processes $\prod_{i=1}^{k} \pi_{i}^{1}$ received by method of similarity of functioning of technical systems [9] were used.

At the same time were compared calculated for a reference sample - an analog value of the generalized criterion of similarity - the material analog establishing functional connection between indicators of physicomechanical properties, and parameters of its processing and value of the generalized criterion of the similarity calculated $\prod_{i=1}^{k} \pi_{i}^{1}$ for other studied material excellent on the physicomechanical to properties from material analog, but with the same structure of parameters of processing, and in case of inequality of the calculated values of criteria of similarity, other parameters of processing of the studied material before equality performance were selected

$$
\prod_{i=1}^{k} \pi_{i}=\prod_{i=1}^{k} \pi_{i}^{1}[5]
$$

\section{Experimental part}

Research problem at this stage is ensuring automatic control with the IGV modes when performing the corresponding operations: moistening; the subsequent, if necessary, cyclic drying from within preparation of top of footwear; damp thermal treatment [10].

Object of researches is the installation realizing a serial-parallel way of hygrothermal processing of the preparations found from skin of chromic tanning in the form of circles with a diameter of $100 \mathrm{~mm}$ with the concentric circles with a diameter of 40 and $60 \mathrm{~mm}$ applied on them for the subsequent installation on punches. They were exposed to hygrothermal processing on the developed universal installation with adjustable parameters of a working environment [11]. (which design is given further), providing consecutive (with dredging of the samples which are on a nonperforated punch) and serial-parallel, with application of the punched punch [12], performance of operations of moistening, drying and damp thermal treatment in the conditions of a vacuum and without him.

Experimental installation [13] which schematic diagram is provided on the figure 1 has been developed for conducting pilot studies of the modes of hygrothermal processing (moistening, damp and thermal fixing, drying and damp thermal treatment).

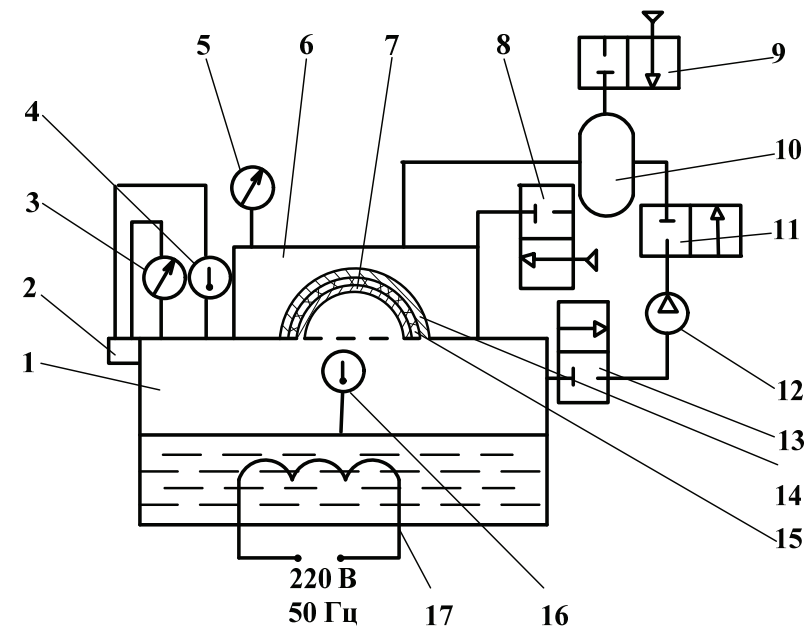

Fig. 1. The Schematic diagram of installation for gigrotermichesky impact on preparations of top of footwear: 1 - the lower vacuum chamber with water; 2 - hardware of the experimental installation; 3, 5- pressure sensors;

4, 16 - temperature sensors; 6 - upper camera; 7 - the punched baffle and a punch; 8,9 - the air supply valve; 10 - air accumulator; 11 - air pumping valve; 12 - vacuum pump; 13 - connective valve; 14 - airfast film; 15 - skin sample; $17-$ TEN.

Are a part of installation upper 6 and the lower 1 vacuum chambers with a total amount of $0,09 \mathrm{~m}^{3}$ which are partitioned punched by a baffle and a punch 7 which the sample of skin 15 is put on and then it is sealed from the upper camera by an airfast film 14 .

Evacuation of the lower camera is carried out by the vacuum pump 12 (type 2NVR-5DM, with a productivity of $5 \mathrm{p} / \mathrm{a}$, with outlet pressure from atmospheric to 0,02 MPas, electromotor of $0,55 \mathrm{~kW}$ ) via the piston valve of control 13. The pumped-out air gathers in the accumulator of air 10 and moves in the upper camera for the additional fixing which is realized as required.

Heating of water in the lower camera realizes the tubular electric heater 16 (the $1 \mathrm{~kW}$ TEN). Tension given on TEN was regulated in the diagram of the hardware of the experimental installation 2 (a figure 1).

Steam to samples in case of a research of processes of hygrothermal influence arrived in case of evaporation of the warmed-up water which is in the lower part of the camera after preliminary evacuation last up to 0,02 MPas.

Ratios between temperature and pressure [14] were supported automatically: when moistening $T=2028 \cdot P^{0,31}$ when drying $T>202,8 \cdot P^{0,31}$ at damp thermal treatment $T<202,8 \cdot P^{0,31}$. 


\section{Approach}

The control system which algorithm is given in the figure 2 is developed for ensuring automatic control with the modes of intensive hygrothermal influence when performing the corresponding operations according to requirements of technological process of production of footwear of genuine leather.

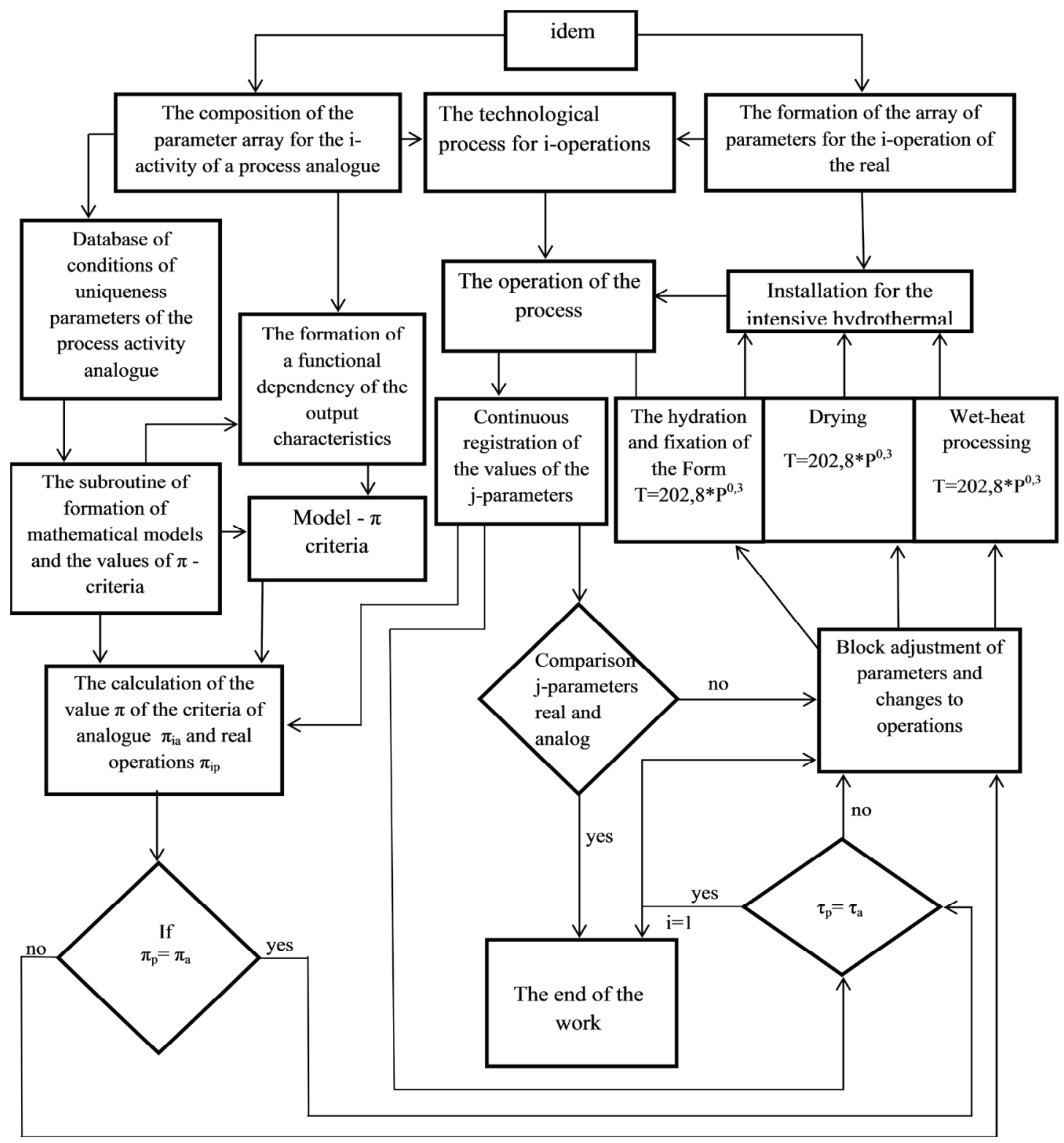

Fig. 2. Scheme of an algorithm of a control system technological processes of IGV

Depending on the chosen technological process of IGV two structures of the massif - for process of an analog and real process which include the parameters defining physicomechanical properties of material, parameters of a working environment and installation are entered into a control system. The number of parameters has to be equal in both massifs. The massif of an analog has to be made on the basis of unambiguity conditions which allow to define value of the parameters corresponding to a certain type of processes of IGV.

On the basis of the program for creation of mathematical models and values $\pi$ criteria the functional dependences of output characteristics of processes of IGV from the parameters defining its status are created.

Based on these data the subprogramme calculates values $\pi$-criteria of an analog $-\pi_{\mathrm{ia}}$ and real process $-\pi_{\mathrm{ip}}$ if the received values match, then the modes corresponding to process analog are applied also to real process. In this case the signal arrives on the unit of comparing where after an output of parameters $\mathrm{T}$ and $\mathrm{P}$ of real process on the curve set by the equation $y=202,8 \cdot x^{0,3}$ when moistening and corresponding to the maximum saturation by moisture of the steam-air environment which is in the accepted volume, the ratio of these parameters is supported to constants during moistening time.

When drying the ratio of temperature and pressure in the set limits during drying time according to inequality is supported $y>202,8 \cdot x^{0,3}$.

At damp thermal treatment the ratio of temperature 
and pressure in the set limits during time of damp thermal treatment according to inequality is supported $y<202,8 \cdot x^{0,3}$.

In that case when values $\pi$ - criteria aren't equal, the signal on the block of regulation of parameters which changes temperature of processing and pressure corresponding to her to the values providing equality $\pi_{\mathrm{ia}}$ and $\pi_{\mathrm{ip}}$ is given. Then process is carried out as it is described above.

\section{Conclusions}

1) When using of the offered algorithm automatic control of parameters of processes of $\mathrm{IGV}$ on preparations of top of footwear in universal vacuum installation upon transition [15] from performance of one operation to another according to standard manufacturing techniques of footwear will be provided [16-18].

2) On a management information cover of skilled installation for hygrothermal processing of skin the certificate of the Russian Federation on the state registration of the computer program No. 2010617180 $[19,20]$ is received.

\section{References}

1. L. V. Larina, N.Yu. Leshina Technical and technological problems of service, n 3, 42-44 (2014)

2., K.M. Zurabyan [etc.] News of higher education institutions. Technology of light industry. No 5, 7580 (1990)

3. L. V. Larina, V. A.Pershin, Engineering bulletin of Don No. 3., (2012) Access mode: http://www.ivdon.ru/ru/magazine/archive/n3y2012/9 02.

4. L. V. Larina, Pershin V. A., Smirnov V.V., Dzheliyev Yu.O. News of higher educational institutions. North Caucasus region. Technical science, No., 2012, 129132

5. L. V. Larina, V.I. Yurchenko, News of higher education institutions. Sowing, No. 6. 140-145, (2011)

6. L. V. Larina, News of higher education institutions. Sowing, No. 1, 129-132 (2012)

7. L.V. Larina, V. V. Karaschenko World Applied Sciences Journal, 29, N. 12. (2014) Access mode: http://www.idosi.org/wasj/wasj/29\%2812\%292014.h tm

8. L.V. Larina, V.A. Pershin [etc.] The Engineering Bulletin of Don, No. 3 (2012) Access mode: http:/www.ivdon.ru/ magazine/latest/n3y2012/896/

9. V. A. Pershin, Methodology of similarity of functioning of technical systems (monograph) (YuRGUES, Shakhty) (2004)

10. L.V. Larina Vacuum and capillary gigrotermichesky processing of skin (ISoIP (branch) of DGTU Shakhty, 2014)
11. L. V. Larina, V.V. Smirnov, B.I. Surmilov, V.A. Soroka, S.A. Tryapichkin, Pat. 2414832 Russian Federation, MPK6 And 43 D 11/00.

12. Larina L.V., Smirnov V. V., Tikhonova O. B., Smirnova E. I. Pat. No. 2537160 Russian Federation, MPK A43D 11/00/

13. L.V. Larina, B.I. Surmilov, A.A. Zagoskin, A.A. Maly, 2312574 Dews. Federation of MPK6, A 43 D $95 / 10$

14. S.L. Rivkin, A.A. Alexandrov, Heatphysical properties of water and water vapor (Moscow, Energy, 1980)

15. L.V. Larina, Proceedings of IGTA conference, (Progress-2012), Ivanovo, 163-164 (2012)

16. Larina L.V. Modern science: current problems of the theory and practice. It is gray.: Natural and technical science. No. 3-4, 53-55 (2014)

17. L. V. Larina, Leshina N.Yu., Smirnov V.V. Current problems of the equipment and technology: proceedings, Shakhty, 158-162 (2014)

18. L. V. Larina, Household appliances, technology and equipment of the housing and public utilities enterprises, service and mechanical engineering: proceedings, Shakhty: FGBOU VPO of "YuRGUES", 48-49 (2013)

19. L. V. Larina. Smirnov V.V., Cherunova I.V., Lebedeva of E.O. Merkulov A. V., Modern problems of science and education, No. 6 (2013) Access mode: http://online.rae.ru/1656.

20. L.V. Larina, I.V. Tarara, V.V. Smirnov, Certificate of the Russian Federation on the state registration of the computer program No. 2010617180 